\title{
Identification and DNA sequence of $t d c R$, a positive regulatory gene of the tdc operon of Escherichia coli
}

\author{
Herbert P. Schweizer and Prasanta Datta \\ Department of Biological Chemistry, University of Michigan, Medical School, Ann Arbor, MI 48109-0606, USA
}

\begin{abstract}
Summary. Efficient in vivo expression of the biodegradative threonine dehydratase $(t d c)$ operon of Escherichia coli is dependent on a regulatory gene, $t d c R$. The $t d c R$ gene is located 198 base pairs upstream of the $t d c$ operon and is transcribed divergently from this operon. The nucleotide sequence of $t d c R$ and two unrelated reading frames has been determined. The deduced amino acid sequence of TdcR indicates that it is a polypeptide of $M_{r} 12000$ with 99 amino acid residues and contains a potential helix-turnhelix DNA binding motif. Deletion analysis and minicell expression of the $t d c R$ gene suggest that TdcR may serve as a trans-acting positive activator for the $t d c$ operon.
\end{abstract}

Key words: Gene regulation - $t d c$ operon - Escherichia coli $-t d c$ activator

\section{Introduction}

The structural gene $(t d c B)$ for the anerobically induced biodegradative threonine dehydratase (EC 4.2.1.16) of Escherichia coli has previously been cloned in this laboratory on a 6.3 kilobase pair (kb) EcoRI fragment (Goss and Datta 1985). Subcloning and DNA sequence and insertion analysis revealed that $t d c B$ is part of a single transcriptional unit, the $t d c$ operon, that contains three genes: $t d c A, t d c B$ and $t d c C$ (Goss et al. 1988). In minicells, these genes directed the synthesis of polypeptides with apparent molecular weights of 32,35 and 45 kilodaltons ( $\mathrm{kDa}$ ), respectively. Whereas the $35 \mathrm{kDa}$ protein was identified as threonine dehydratase (Goss and Datta 1985; Datta et al. 1987), the functions of the $32 \mathrm{kDa}$ and $45 \mathrm{kDa}$ proteins still remain unknown. In an earlier report, Hobert and Datta (1983) showed that anaerobic expression of the $t d c B$ gene has an absolute requirement for four amino acids, threonine, serine, valine and isoleucine, plus an electron acceptor, fumarate, and cyclic AMP. They postulated that some metabolite(s) derived from these amino acids during anaerobic metabolism is needed for dehydratase induction. In addition, the enzyme is subject to catabolite repression control by rapidly utilizable carbohydrates (Umbarger 1978; Hobert and Datta 1983). In this report we present evidence that efficient expression of the $t d c$ operon is positively regulated by a gene located upstream of the $t d c$ promoter.

Offprint requests to: $\mathrm{P}$. Datta

\section{Materials and methods}

Bacterial strains. Strain DH5 $\alpha \mathrm{F}^{\prime}\left(\mathrm{F}^{\prime} \phi 80 d\right.$ lacZAM15 $\Delta$ (lacZYA-argF)U169 recA1 endA1 hsdR17 $\left(\mathrm{r}_{\mathrm{k}}^{-} \mathrm{m}_{\mathrm{k}}^{+}\right) \operatorname{supE44} \lambda^{-}$ thi-1 gyrA relA1 (Bethesda Research Laboratories, Gaithersburg, $\mathrm{Md}$ ) was used as a host for selection and maintenance of plasmids. Strain X1411 ( $\mathrm{F}^{-} \mathrm{g} \ln U 42 \min A 1 \min B 1$ $\lambda^{-}$) (Clark-Curtiss and Curtiss 1983) was used for isolation of minicells. TdcB-LacZ fusions were assayed in strain DL291 $\left(\mathrm{F}^{-} \Delta\right.$ (argF-lac $) U 169$ araD139 rpsL150 relA1 thiA1 deoC1 ptsF25 flbB5301 rbsR glpR2 A(glpT-glpA)593 gyrA recA1) (Ludtke et al. 1982).

Growth media. Media were prepared according to Miller (1972) and Davis et al. (1980). If needed, antibiotics were added at the following concentrations: $100 \mu \mathrm{g} / \mathrm{ml}$ ampicillin (Ap), and $50 \mu \mathrm{g} / \mathrm{ml}$ kanamycin $(\mathrm{Km})$. Lactose phenotypes were screened on LB plates (Miller 1972) containing 40 $\mu \mathrm{g}$ of 5-bromo-4-chloro-3-indolyl $\beta$-D-galactopyranoside (XGal) per $\mathrm{ml}$.

Plasmids. Plasmid pSH207 was constructed by deleting a $3.7 \mathrm{~kb}$ Sall fragment of pEC61 (Fig. 1; Goss and Datta 1985 ) and contains $2.6 \mathrm{~kb}$ of chromosomal DNA. For the construction of the fusion plasmid pFR6, a 303 bp DraI fragment of pSH207 containing the first 66 codons of the $t d c R$ gene was ligated to $S m a I$ cleaved pMC1403 DNA (Casadaban et al. 1980). This procedure fused codon 66 of $t d c R$ in-frame to codon 8 of $l a c Z$. For the construction of the fusion plasmid pFR1, a 368 bp HincII fragment of plasmid pSH266, harboring the $t d c R$ gene on a $600 \mathrm{bp}$ DraI-EcoRI fragment from pBal4 in pUC19, was ligated to SmaI cleaved pMC1403 DNA. This procedure fused codon 82 of the $t d c R$ gene in-frame to codon 8 of lac $Z$. The correct fusion constructs were verified by DNA sequence analysis (data not shown). pBa14, pBa19, pBal11 and pTG122 were from a previous collection of nested deletions (Goss and Datta 1985; T.J. Goss, PhD Thesis, University of Michigan 1986) generated by Bal31 treatment of the $E c o$ RI terminus of pTG4B. The purified EcoRI-HindIII fragments from pTG4B and these deletion plasmids, carrying decreasing lengths of sequences upstream of the HindIII site, were ligated separately to the HindIII site of $\mathrm{pSH} 202$ to generate plasmids pSH238, pSH242, pSH241 and pSH240 (Fig. 1). The construction of pSH202 harboring the $t d c B-l a c Z$ fusion has been described previously (Schweizer and Datta 1988). pSH239 was constructed by 
A

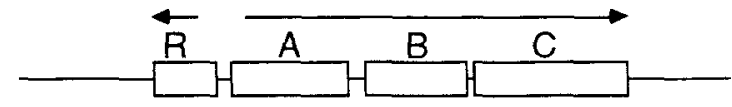

pEC61
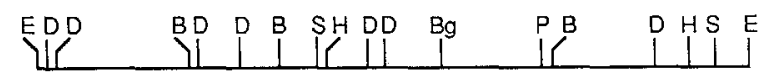

pTG4B

pSH207

pSH243

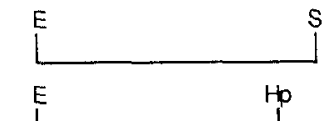

B

pSH202

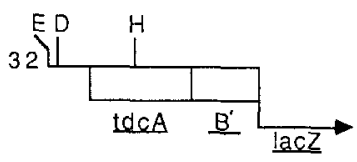

$\%$ specific LacZ activity

3

pSH240

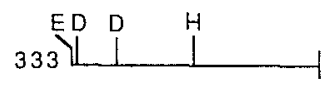

35

pSH24

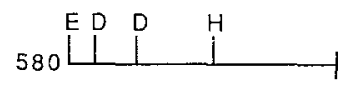

pSH242

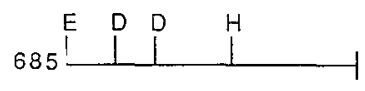

98

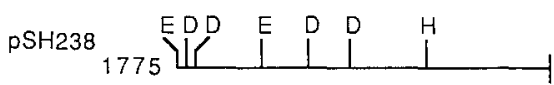

100

Fig. $1 \mathrm{~A}$ and B. Physical structure of the $t d c$ region and the effect of upstream sequences on $t d c$ expression. A Restriction maps of plasmids discussed in the text. Abbreviations: $\mathrm{B}, B c I \mathrm{I}$; $\mathrm{Bg}, B g / \mathrm{II}$; D, DraI; E, EcoRI; H, HindIII; Hp, Hpal; P, PstI; S, SalI. B Effect of upstream sequence on $t d c$ expression. A nested set of deletions extending from the EcoRI (E) site of pTG4B was obtained by Bal31 treatment. The deletion end-points were determined by DNA sequence analysis (see Fig. 3). The numbers next to the EcoRI sites of various plasmids represent distances in bp from the first nucleotide of the Dral site upstream of $t d c A$. $\beta$-Galactosidase activity from the indicated plasmids was measured in strain DL291 (4lac) grown aerobically in LB medium and $\beta$-galactosidase activity expressed from $\mathrm{pSH} 238$ was arbitrarily set at $100 \%$

ligating a $3.7 \mathrm{~kb} E c o \mathrm{RI}-P v u \mathrm{II}$ fragment from pSH207, containing $2.3 \mathrm{~kb}$ of the upstream sequence plus $1.4 \mathrm{~kb}$ pBR322 DNA, with pACYC184 (Chang and Cohen 1978) previously digested with $E c o$ RI and $P v u \mathrm{II}$.

Plasmid pSH243 (Fig. 1) was constructed by cloning a $2.0 \mathrm{~kb}$ EcoRI-HpaI fragment of pSH207 into EcoRI-SmaI cleaved pUC13 (Vieira and Messing 1982) DNA. For the construction of pSH245, pSH243 was first passed through dam $^{-}$strain GM33 (G. Marinus via Bethesda Research Laboratories), cleaved with $B c I I$, and then ligated to a $1.4 \mathrm{~kb} \mathrm{BamHI}$ kanamycin-resistance gene cassette isolated from pUC4K (Vieira and Messing 1982). The transcriptional orientation of the kanamycin-resistance gene in pSH245 is opposite to that of the $t d c$ operon.

DNA sequence analysis. DNA fragments were isolated from low-melting agarose gels as described by Wieslander (1979).
Cloning of DNA fragments into M13mp18 and M13mp19 and isolation of single stranded template DNA were carried out as described by Messing (1983). Sequence analysis by the dideoxy chain termination procedure was performed utilizing the Sequenase ${ }^{\mathrm{TM}}$ kit and the protocol provided by the supplier (United States Biochemicals, Cleveland, Ohio). Labeled DNA fragments were separated in buffer gradient gels as described by Biggin et al. (1983).

Purification and labeling of minicells. Minicells were purified, labeled and analyzed as previously described (Goss et al. 1988). In some experiments, protein patterns were analyzed on tricine-sodium dodecylsulfate-polyacrylamide gels as described by Schägger and von Jagow (1987).

Other methods. Restriction enzymes, Klenow DNA polymerase and T4 DNA ligase were purchased from Bethesda Research Laboratories (Rockville, Md), Boehringer Mannheim Biochemicals (Indianapolis, Ind) or International Biotechnologies (New Haven, Conn) and were utilized according to the supplier's specifications. DNA sequences were analyzed using the Beckman MicroGenie software (Beckman Instruments, Palo Alto, Calif).

\section{Results}

Effect of upstream sequences on tdc expression

While studying the extent of DNA needed for $t d c B$ expression, Goss and Datta (1985) found that 159 base pairs (bp) of nucleotide sequence upstream of the first codon of $t d c A$ present in pTG122 was sufficient for dehydratase synthesis. However, pTG122 expressed only appiroximately $27 \%$ of the activity expressed from pTG4B, a plasmid containing ca. $1.9 \mathrm{~kb}$ of upstream DNA (Fig. 1). This result indicates that upstream sequences might be required for efficient expression of the $t d c$ genes. To examine in detail the effect of upstream sequences on $t d c$ expression, a set of nested deletions extending from the EcoRI end of pTG4B was fused with lac $Z$ as described in Materials and methods, and $t d c$ expression was monitored by measuring the $t d c B-$ $l a c Z$ encoded $\beta$-galactosidase activity. The results shown in Fig. 1 clearly demonstrate that DNA sequences located within ca. $700 \mathrm{bp}$ upstream of the $t d c A$ coding region are required for optimal $t d c$ expression.

A careful comparison of $\beta$-galactosidase activity expressed from $\mathrm{pSH} 202$, pSH240 and pSH241 revealed an interesting aspect of $t d c B-l a c Z$ expression: plasmid pSH240, which contained an extra $300 \mathrm{bp}$ of DNA upstream from the end of pSH202, exhibited significantly higher levels of $\beta$-galactosidase activity as compared to those produced by pSH202 but failed to express enzyme activity maximally as that seen with $\mathrm{pSH} 241$; the latter plasmid contained an additional segment of upstream DNA of about $250 \mathrm{bp}$ (Fig. 1). One possible interpretation of the data is that pSH241, but not pSH240, encodes a specific protein which is necessary for optimal expression of $t d c$, and that pSH240 contains a DNA sequence that is needed in cis for transcriptional activation; pSH202 lacks this cis sequence, resulting in basal levels of enzyme expression. The intermediate level of $t d c-l a c Z$ expression in pSH240 would presumably reflect transcriptional activation mediated by the chromosomally-encoded activator protein. 


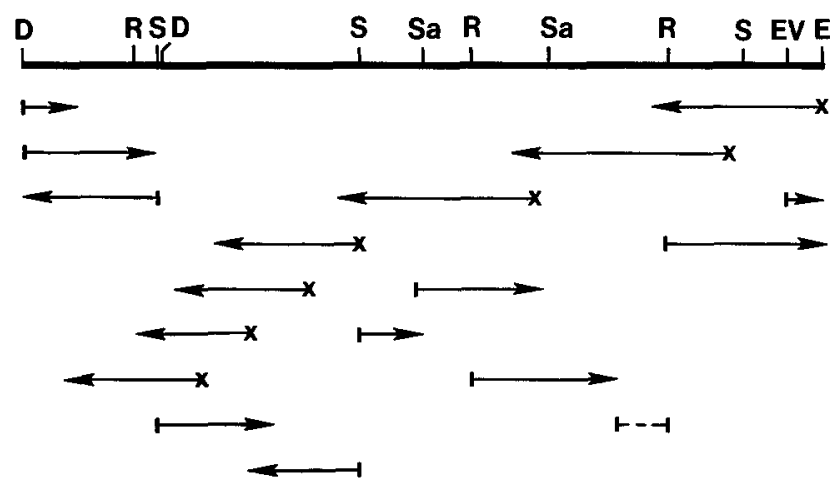

Fig. 2. Sequencing strategy. Sequence information was obtained from clones that were constructed by: (1) cloning fragments derived from a nested set of Bal31 deletions into M13mp19 (marked $\mathrm{x}$ ); and (2) directed cloning of fragments into M13mp18 or M13mp19 (marked I). Both strands were sequenced with the exception of ca. 100 bp (marked - - - ) which was sequenced twice on the same strand. Abbreviations: D, DraI; E, EcoRI; EV, EcoRV; R, $R s a \mathrm{I} ; \mathrm{S}, S s p \mathrm{I}$; Sa, Sau3AI

To test this notion, strain DL291 harboring pSH202 or $\mathrm{pSH} 240$ was transformed with the compatible plasmid pSH239 containing the entire $1.9 \mathrm{~kb}$ upstream sequences. tdcB-lacZ expression from pSH240 was stimulated 3- to 5-fold by the presence of pSH239, whereas expression from pSH202 was unaffected (data not shown). These results provide strong evidence that a specific protein might be encoded by the upstream sequences which is acting in trans as a transcriptional activator at the $t d c$ promoter. The results further suggest that a potential cis-acting sequence(s) necessary for transcriptional activation is present on $\mathrm{pSH} 240$ but not on pSH202. From the data presented in Fig. 1 it is evident that the structural gene for the putative $t d c$ activator protein (designated $t d c R$ ) must be located between the left boundary of pSH202 and the left boundary of pSH241 (as depicted in Fig. 1), encompassing ca. $600 \mathrm{bp}$ of DNA.

\section{Nucleotide sequence of the tdcR region}

Figure 2 outlines the strategy used to determine the nucleotide sequence of the entire upstream region (displayed in inverted orientation) between the DraI site located $130 \mathrm{bp}$ upstream of the $t d c A$ coding region and the EcoRI site representing the left-most boundary of the cloned chromosomal DNA. Both strands were sequenced with the exception of ca. $100 \mathrm{bp}$ which were sequenced twice on the same strand. All restriction sites indicated in Fig. 2 were verified by restriction enzyme digestion except a $H p a I$ site at nucleotide 721 (Fig. 3 ; not shown in Fig. 2) that could only be verified by nucleotide sequence analysis. The nucleotide sequence of the coding strand, presented in Fig. 3, revealed two complete open reading frames (orf) corresponding to nucleotides 106-402 and 661-1197, and a third partial orf starting from nucleotide 1222 (numbered from the DraI site at the $5^{\prime}$ end). No other open reading frames were detected in the same or on the opposite strand. Based on the extent of $t d c-l a c Z$ expression from various plasmids (see Fig. 1), the 297 bp long first orf most likely represents the putative $t d c R$ gene product: plasmid pSH241, which extends up to nucleotide 580, harbors the complete coding
DraI PSH202

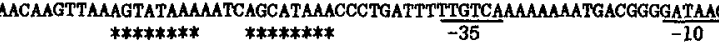
CATATTTTATGGCGATAACATCATCGITAT GTG GTT AAT ACA AAA AAG GGG CTG AGA CCA TAT Val Val As

TTC AAG CAA TTA CCG GAT AAT TAC CAG GCA AAA TTT GAG TTA AAT TTA ATG AGC AAG Phe Lys Gln Leu Pro Asp Asn Tyr Gln Ala Lys Phe Glu Leu Asn Leu Met Ser lys Phe Lys Gln Leu Pro Asp Asn Tyr Gln Ala Lys Phe Glu Leu Asn Leu Met Ser lya TTC TCA AAT TTT ATT ATA AAT AAA CCA TTT TCA GTG ATA AAT AAT GCG GCA TGT CAC Phe Ser Asn Phe Ile Ile Asn Lys Pro Phe Ser Val Ile Asn Asn Ala Ala Cys His ATT TTT TCA CGG TAT TTG TTG GAG AAC AAA CAT TTA TTT TAT CAA TAT TRT AAA ATT Ile Phe Ser Arg Tyr Leu Leu Glu Asn Lys His Leu Phe Tyr Gln Tyr Phe Lys Ile TCG AAT ACA TGT ATT GAT CAT CTC GAA CAA TTG ATT AAC GTC AAC TTT TTC TCT TCT Ser Asn Thr Cys Ile Asp His Leu Glu Gin Leu Ile Asn Val Asn Phe Phe Ser Ser GAC AGG ACG TCA TTT TGT GA TGC AAT CGT TTT CCA TAA ATTCTTCTCCCCTCATAGGCGAC Asp Arg Thr Ser Phe Cys Glu Cys Asn Arg Phe Pro ***
Asp Arg Thr Ser Pho GAATAGCATTTTGTGTTGAGGATCACAAAACGAATAATTGCTGATCGCCGCGATAAGGTCAGACAAAGACAACA GGGAAATTTTCACAGAGCIT"TTGATCGGCGTAGGCCACAGATTGTTGCTTCGTTTACTGTAACGCCGGTAAATO ᄀ
AGCGTTTTTTGATAGTGCGAAAGAACCCTGCGAGGAAAATAAGCATCTATTATTGTTTGTCATGATGACAAGGCA
$\frac{-35}{-10}$ PSH242

GGCATCA ATG AMA GGC TTC CCA ATT GCG CAT ATT TTT CAC CCT TCA ATC CCG CCA ATE Met Lys gly Phe Pro Ile Ala His Ile Phe His Pro Ser Ile Pro Pro Met

CAC GCA GTG GTET AAC AAT CAC AAT AGA SAT ATT GAT TAT TGG ACG GTA AMA AGA AAG His Ala Val Val Asn Asn His Asn Arg Asn Ile Asp Tyr Trp Thr Val Lys arg Lys TTT GCA GAA ATT GTC TCC ACC AAT GAC GTT AAT AAA ATT TAC AGT ATA hGT AAT GAA Phe Ala Glu Ile Val Ser Thr Asn Asp Val Asn Lys I le Tyr Ser Ile Ser Asa Glu 850

CTG CGG AGA GTA TTA TCT GCA ATA ACT GCA TTG AAT TTC TAT CAT GGC GAT GTT CCT Leu Arg Arg Val Leu Ser Ala Ile Thr Ala Leu Asn Phe Tyr His Gly Asp Val Pro 900

TCT GTC ATG ATC CGA ATC CAA CCG GAA AAT ATG AGT CCA TTC ATT ATA GAT ATT TCT Ser Val Met Ile Arg Ile GIn Pro glu asn Met Ser Pro Phe Ile Ile Asp Ile Ser 950

ACA GGA GA CAT GAT GAT TAT ATC ATA CAA ACA TTA GAT GTA GGC ACT TTT GCA CCT Thr Gly Glu His Asp Asp Tyr Ile Ile Gln Thr Leu Asp Vel Gly thr Phe Ala Pro

1000
TTT GGT GAA GAA TET ACT TGC TCA GCC GTC AAT AAA AAA GAG CTG GAA TGT ATT AAG 1050 Phe Gly Glu GIn Cys thr Cys Ser Ala Val Asn Lys Lys Glu Leu glu Cys Ile Lys 1100

GAG ACG ATT TCT AAG TAT TGT GCA AAA TTC ACC CGA AAA GAA GCC ATC TTA ACC CCC Glu Thr Ile Ser Lys Tyr Cys Ala Lys Phe Thr Arg Lys Glu Ala Ile Leu Thr Pro CTT GTG GAC TTT AAT AAA ACC AGC ATT ACT TCA GAT TGT TGG CAA ATT CTC TTT TTT Leu Val His Phe Asn lys Thr Ser Ile Thr Ser Asp Cys Trp Gln Ile Leu Phe Phe 1200

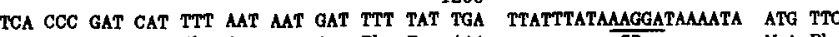
Ser Pro Asp His Phe Asn Asn Asp Phe Tyr *** 1250 SD CCT GTT TCA TCA ATT GGT AAT GAT ATT AGT AGT GAT TTA GTC CGT CGA AAA ATG AAT Pro Val Ser Ser Ile Gly Asn Asp Ile Ser Ser Asp Leu Val Arg Arg lys Met Asn 1300

GAC CTT CCT GAA AGC CCA ACA GGA AAT AAC CTC GAA GCA CTA GCA CCA GGT ATA GAA Asp Leu Pro Glu Ser Pro Thr gly Asn Asn Leu glu ala leu ala Pro Gly Ile glu Asp Lau Pro

AA CTA AAA CAG ACC TCT ATT GAA ATG GTC ACT TTA CTT AAC ACG TTA CAA CCT GGT Lys Leu Lys Gln Thr Ser Ile Glu Met Val Thr Leu Leu Asn Thr Leu Gln Pro Gly GGA AAA TGC ATT ATC ACT GGT GAT TTT CAA AAA GAA TTA GCG TAC TTA CAA AAT GTA Glu Lys Cys Ile Ile Thr Gly Asp Phe Gln bys Glu Leu Ala Tyr Leu Gln Asn Val 1500

ATT CTT TAT AAT GTC TCG TCT CTT COT CTO GAT TTT TTA GOT TAT AAC GCC CAA AT Ile leu Tyr Asn Val Ser Ser Leu Arg Leu Asp Phe Leu Gly Tyr Asn Ala Gln Ile PVII 1550

ATT CAA CGA TCG GAC AAT ACT TGT GA CIT ACC ATT AAT GAA CCO TTA AAA AAC CAG Ile Gln Arg Ser Asp asn Thr Cys Glu Leu Thr Ile san Glu Pro Leu Lys Asn Gln

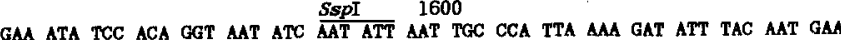
Glu Ile Ser Thr Gly asn Ile Asn Ile Aon Cys Pro Leu Lys asp Ile Tyr Asn gin Glu Ile Ser Thr Gly Asn Ile Asn Ile Aon Cys Pro heu Lys Asp Tle Tyr Asn Gin ATC AGG AGG TTA AAC GTA ATT TTT AGT TGT GGG ACT GGA GAT ATC GTT GAT CTA TCC Ile Arg Arg Leu Asn Val Ile Phe Ser Cys Gly Thr Gly Asp Ile Val Asp Leu Ser TCT CTG GAC TTA CGT AAT GTC GAT TIPA GAT TAT TAT GAT TTC ACA GAT AAA CAT ATG Ser Leu Asp Leu Arg Asn Vel Asp Leu Asp Tyr Tyr Asp Phe Thr Asp lys His Met GCT AAT ACT ATT TTA AAT CCT $\frac{\text { DraT }}{\text { TTT AAA TTG AAT TC }} 1775$ Ala Asn Thr Ile Leu Asm Pro Phe Lys Leu Asn

Fig. 3. Nucleotide sequence of the upstream region. The nucleotide number is assigned arbitrarily, beginning with the first nucleotide of the Dral site located upstream of $t d c A$. Putative promoter consensus sequences $(-10$ and -35$)$ and ribosome binding sites (SD) of the open reading frames $t d c R$, orf $A$ and $\operatorname{orf} B$ are indicated. An asterisk below the line marks a repeated sequence with the consensus AGPyATAAA. The arrowhead marks the fusion joints of the TdcR-LacZ fusion proteins. Also indicated is a possible weak transcriptional terminator for $t d c R$ 
Table 1. Codon usage in $t d c R^{\mathrm{a}}$

\begin{tabular}{|c|c|c|c|c|}
\hline Amino acid & Codon & $t d c R$ & $\mathrm{~S}$ & W \\
\hline $\mathrm{Ala}$ & $\begin{array}{l}\text { GCU } \\
\text { GCC } \\
\text { GCA } \\
\text { GCG }\end{array}$ & $\begin{array}{l}0 \\
0 \\
2 \\
1\end{array}$ & $\begin{array}{r}33 \\
9 \\
23 \\
25\end{array}$ & $\begin{array}{l}17 \\
34 \\
20 \\
28\end{array}$ \\
\hline Arg & $\begin{array}{l}\text { CGU } \\
\text { CGC } \\
\text { CGA } \\
\text { CGG } \\
\text { AGA } \\
\text { AGG }\end{array}$ & $\begin{array}{l}1 \\
1 \\
0 \\
0 \\
1 \\
1\end{array}$ & $\begin{array}{l}42 \\
19 \\
1 \\
0.2 \\
1 \\
0.2\end{array}$ & $\begin{array}{r}19 \\
25 \\
5 \\
8 \\
5 \\
3\end{array}$ \\
\hline Asn & $\begin{array}{l}\text { AAU } \\
\text { AAC }\end{array}$ & $\begin{array}{l}9 \\
3\end{array}$ & $\begin{array}{r}2 \\
30\end{array}$ & $\begin{array}{l}19 \\
19\end{array}$ \\
\hline Asp & $\begin{array}{l}\text { GAU } \\
\text { GAC }\end{array}$ & $\begin{array}{l}2 \\
1\end{array}$ & $\begin{array}{l}22 \\
39\end{array}$ & $\begin{array}{l}35 \\
20\end{array}$ \\
\hline Cys & $\begin{array}{l}\text { UGU } \\
\text { UGC }\end{array}$ & $\begin{array}{l}3 \\
1\end{array}$ & $\begin{array}{l}2 \\
4\end{array}$ & $\begin{array}{l}6 \\
7\end{array}$ \\
\hline Gln & $\begin{array}{l}\mathrm{CAA} \\
\mathrm{CAG}\end{array}$ & $\begin{array}{l}3 \\
1\end{array}$ & $\begin{array}{r}7 \\
32\end{array}$ & $\begin{array}{l}17 \\
32\end{array}$ \\
\hline Glu & $\begin{array}{l}\text { GAA } \\
\text { GAG }\end{array}$ & $\begin{array}{l}2 \\
2\end{array}$ & $\begin{array}{l}63 \\
20\end{array}$ & $\begin{array}{l}40 \\
19\end{array}$ \\
\hline Gly & $\begin{array}{l}\text { GGU } \\
\text { GGC } \\
\text { GGA } \\
\text { GGG }\end{array}$ & $\begin{array}{l}0 \\
0 \\
0 \\
1\end{array}$ & $\begin{array}{r}43 \\
33 \\
1 \\
3\end{array}$ & $\begin{array}{r}24 \\
27 \\
8 \\
13\end{array}$ \\
\hline His & $\begin{array}{l}\text { CAU } \\
\text { CAC }\end{array}$ & $\begin{array}{l}2 \\
1\end{array}$ & $\begin{array}{r}4 \\
14\end{array}$ & $\begin{array}{l}18 \\
11\end{array}$ \\
\hline Ile & $\begin{array}{l}\text { AUU } \\
\text { AUC } \\
\text { AUA }\end{array}$ & $\begin{array}{l}5 \\
0 \\
2\end{array}$ & $\begin{array}{l}13 \\
15 \\
0.4\end{array}$ & $\begin{array}{r}30 \\
23 \\
5\end{array}$ \\
\hline
\end{tabular}

a Codon usage in $t d c R$ is compared with that in strongly (S) and weakly (W) expressed Escherichia coli genes (tabulated by Grosjean and Fiers 1982). The $t d c R$ data are for a total of 99 codons; the Grosjean and Fiers data are for a relative usage per 1000 codons

sequence of the polypeptide and shows maximum expression of $\beta$-galactosidase, whereas plasmid $\mathrm{pSH} 202$ lacks the coding sequence and shows only basal levels of LacZ activity. The $73 \mathrm{bp}$ untranslated region between the end of pSH202 and the start of the putative $t d c R$ polypeptide could easily accommodate a potential $c i s$-site for transcription activation. As mentioned above, this sequence present in pSH240 may stimulate transcription to a significant level by interacting with the activator polypeptide encoded by the chromosomal $t d c R$ gene.

The results displayed in Figs. 1 and 3 clearly indicate that the $t d c R$ open reading frame is oriented in the opposite direction to that of the $t d c$ genes. The region preceding the $t d c R$ coding sequence contains recognizable -10 and -35 consensus $E$. coli promoter sequences, and a weak Shine-Dalgarno translation initiation sequence precedes the initiating GUG codon (Fig. 3). A stretch of 258 nucleotides separates $t d c R$ from orf $A$; orf $B$ is located 24 bp downstream from the $3^{\prime}$ end of orf $A$ and extends beyond the $E c o$ RI site. From the sequence data, both orf $A$ and orf $B$ are preceded by strong Shine-Dalgarno sequences, however, only orf $A$ is preceded by a sequence typical of $E$. coli promoters. It is conceivable that $\operatorname{orf} A$ and $\operatorname{orf} B$, but not $t d c R$, are part of a single transcriptional unit (see below).

\begin{tabular}{|c|c|c|c|c|}
\hline Amino acid & Codon & $t d c R$ & $\mathrm{~S}$ & W \\
\hline \multirow[t]{6}{*}{ Leu } & UUA & 4 & 2 & 14 \\
\hline & UUG & 3 & 3 & 12 \\
\hline & CUU & 0 & 5 & 14 \\
\hline & CUC & 1 & 6 & 13 \\
\hline & CUA & 0 & 1 & 4 \\
\hline & CUG & 1 & 66 & 56 \\
\hline \multirow[t]{2}{*}{ Lys } & AAA & 5 & 49 & 31 \\
\hline & $\mathrm{AAG}$ & 3 & 20 & 8 \\
\hline Met & AUG & 1 & 27 & 25 \\
\hline \multirow[t]{2}{*}{ Phe } & UUU & 9 & 7 & 29 \\
\hline & UUC & 3 & 22 & 19 \\
\hline \multirow[t]{4}{*}{ Pro } & $\mathrm{CCU}$ & 0 & 4 & 6 \\
\hline & $\mathrm{CCC}$ & 0 & 0.4 & 9 \\
\hline & CCA & 3 & 5 & 9 \\
\hline & $\mathrm{CCG}$ & 1 & 31 & 19 \\
\hline \multirow[t]{6}{*}{ Ser } & UCU & 2 & 18 & 7 \\
\hline & UCC & 0 & 17 & 9 \\
\hline & UCA & 4 & 1 & 7 \\
\hline & UCG & 1 & 2 & 12 \\
\hline & AGU & 0 & 2 & 11 \\
\hline & AGC & 1 & 9 & 12 \\
\hline \multirow[t]{4}{*}{ Thr } & $\mathrm{ACU}$ & 0 & 20 & 9 \\
\hline & ACC & 0 & 26 & 23 \\
\hline & ACA & 2 & 3 & 6 \\
\hline & $\mathrm{ACG}$ & 1 & 5 & 15 \\
\hline Trp & UGG & 0 & 5 & 13 \\
\hline \multirow[t]{2}{*}{ Tyr } & UAU & 4 & 6 & 18 \\
\hline & UAC & 1 & 19 & 12 \\
\hline \multirow[t]{4}{*}{ Val } & GUU & 1 & 37 & 21 \\
\hline & GUC & 1 & 8 & 13 \\
\hline & GUA & 0 & 23 & 9 \\
\hline & GUG & 2 & 16 & 24 \\
\hline
\end{tabular}

\section{Expression of cloned DNA in minicells}

The deduced amino acid sequences of the three reading frames reveal that the putative $t d c R$ polypeptide consists of 99 amino acid residues with a calculated $\mathrm{M}_{\mathrm{r}}$ of 11816 ; in addition, orf $A$ and $\operatorname{orf} B$ encode polypeptides of $\mathrm{M}_{\mathrm{r}} 20579$ and 20649 , respectively, the latter representing a truncated molecule originating from a larger protein of unknown molecular size. An analysis of the $t d c R$ polypeptide indicates that the codon usage of $t d c R$ is relatively random, and a comparison with the codon preference statistics of weakly and strongly expressed $E$. coli genes, compiled by Grosjean and Fiers (1982), suggests that $t d c R$ would have a low level of expression (Table 1). In accordance with these predictions, minicell analyses of protein patterns expressed by plasmids harboring the upstream region revealed three polypeptides: a polypeptide of approximately $22 \mathrm{kDa}$, most likely representing $\operatorname{orf} A$; a weakly expressed $21 \mathrm{kDa}$ polypeptide presumably originating from the truncated orf $B$; and a very weak, barely visible polypeptide of about 12 $\mathrm{kDa}$ approximating the predicted size of the $t d c R$ gene product (Fig. 4A, lane 2). Interruption of transcription at the single $B c l$ I site located within $t d c R$ (Fig. 3) by insertion of a $1.4 \mathrm{~kb}$ kanamycin-resistance gene cassette from 
A

B

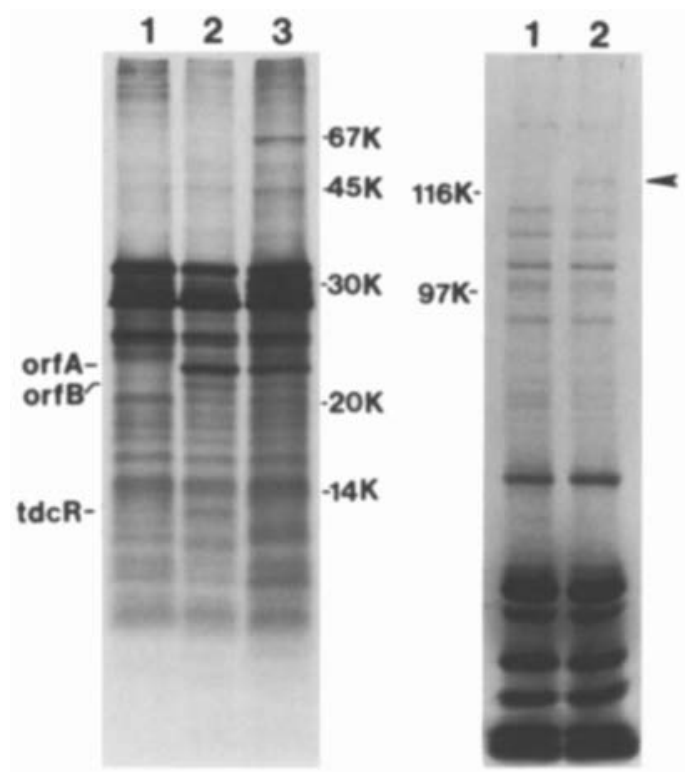

Fig. 4A and B. Expression of proteins in minicells. A Minicells harboring the indicated plasmids were labeled with $\left[{ }^{35}\right.$ S]methionine and proteins were separated in a $16 \% \mathrm{~T} 3 \% \mathrm{C}$ SDS-polyacrylamide gel as described by Schägger and Jagow (1987). Lane 1, X1411/ pUC12; lane 2, X1411/pSH243; lane 3, X1411/pSH245. Numbers to the right indicate the molecular masses in $\mathrm{kDa}(\mathrm{K})$ of the size markers. The positions of plasmid-encoded proteins are indicated to the left. B Minicells harboring the indicated plasmids were labeled with ${ }^{35}$ S $]$ methionine and proteins were separated in a $8 \%$ SDS-polyacrylamide gel. Lane 1, X1411/pMC1403; lane 2, X1411/ pFR6. The arrowhead indicates the position of the TdcR-LacZ fusion protein. Numbers to the left indicate the molecular masses in $\mathrm{kDa}(\mathrm{K})$ of the size markers $(116 \mathrm{~K}$ marks the position of Escherichia coli $\beta$-galactosidase)

pUC4K (Vieira and Messing 1982) abolished the synthesis of the $12 \mathrm{kDa}$ polypeptide but had no effect on the synthesis of the $21 \mathrm{kDa}$ and $22 \mathrm{kDa}$ polypeptides (Fig. 4A, lane 3). These results suggest that the three open reading frames are expressed in vivo, and that $t d c R$ and $\operatorname{orf} A$-orf $B$ belong to different transcriptional units. The functions of the orf $A$ and orf $B$ open reading frames are not known.

As mentioned above, the weak expression of $t d c R$ presumably reflects the poor Shine-Dalgarno sequence as well as poor codon usage. Furthermore, regulatory molecules exist only in a few copies per cell. Another experimental strategy was employed further to examine $t d c R$ expression. Two $t d c R$-lac $Z$ protein fusions (pFR1 and pFR6) were constructed as described in Materials and methods. As judged by growth on LB + XGal plates, both fusions directed the synthesis of low but clearly detectable levels of $\beta$-galactosidase. Plasmid pFR6 was chosen for further analysis. In a $\Delta l a c$ strain it directed the synthesis of about 80 units of $\beta$-galactosidase. It also synthesized in minicells a small amount of a fusion protein of about $125 \mathrm{kDa}$ (Fig. 4B, lane 2) in excellent agreement with the predicted size of $124 \mathrm{kDa}$. In SDS-polyacrylamide gels, the $125 \mathrm{kDa}$ polypeptide co-migrated with affinity-purified TdcR-LacZ protein (data not shown). This result provides further evidence for in vivo expression of $t d c R$ and for the correctness of the assigned reading frame of the $t d c R$ gene.

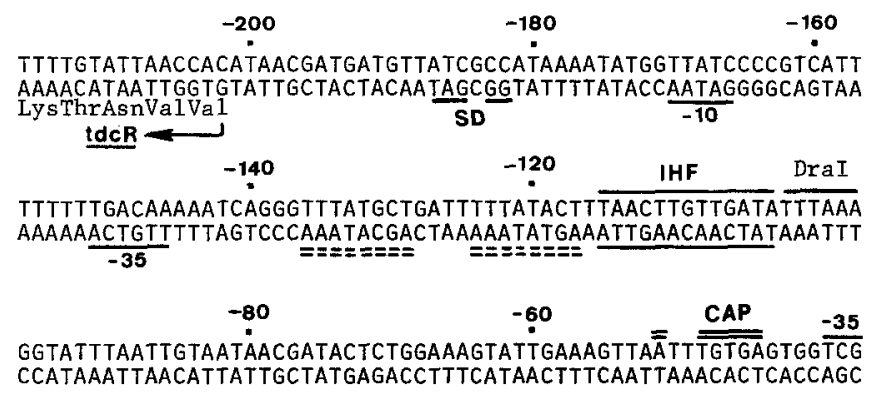

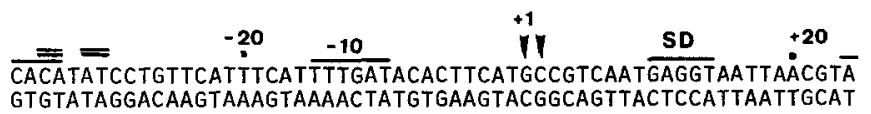

So $\underset{\text { tdcA }}{\text { MetSerThrIIe }}$
GGTCGTTATGAGCACTATT
CCAGCAATACTCGTGATAA

Fig. 5. Structure of the $t d c$ regulatory region. The location of several regulatory sequences known to affect $t d c$ expression are shown. Nucleotides are numbered relative to their positions to the major $t d c$ mRNA start site $(+1)$. The beginning of the $t d c R$ and $t d c A$ coding regions are indicated. Abbreviations: CAP, catabolite gene activator protein binding site; IHF, integration host factor binding site; $==$, AGPyATAAA consensus sequence. Arrowheads denote transcription start sites of $t d c \mathrm{mRNA}$. The putative -35 and -10 sequences, and the ribosome binding sites (SD) are indicated

\section{Discussion}

The experiments described above provide evidence for a regulatory gene, $t d c R$, required for efficient expression of the $t d c$ operon. Nucleotide sequence of the cloned $t d c$ DNA and deletion studies with $t d c B-l a c Z$ fusion plasmids clearly indicate that $t d c R$ is located 232 base pairs upstream of the $t d c A$ gene and is transcribed in opposite orientation to that found for the $t d c$ operon. The amino acid sequence of TdcR, deduced from the nucleotide sequence of the $t d c R$ gene, shows it to be a small polypeptide consisting of 99 amino acid residues with a calculated $\mathrm{M}_{\mathrm{r}}$ of 11816 . The relatively weak expression of TdcR is generally consistent with the presence of a poor Shine-Dalgarno sequence preceding the GUG codon for translation initiation, and the random codon usage statistic correlating with weakly expressed $E$. coli genes. These results are reminiscent of the D-serine deaminase activator gene, $d s d C$, encoding a polypeptide of $33 \mathrm{kDa}$, needed for transcriptional activation of the $d s d A$ gene of $E$. coli. It is interesting to note that $d s d C$ is located 731 base pairs upstream of the translation initiation codon of $d s d A$ and is transcribed divergently from $d s d A$ (Palchaudhuri et al. 1988).

Previous reports from this laboratory suggested that efficient expression of the $t d c$ operon is dependent on the anaerobic metabolism of the four amino acids threonine, serine, valine and isoleucine, in the presence of an electron acceptor such as fumarate or nitrate, and requires cAMP (Hobert and Datta 1983). Although the existence of a consensus CAP binding site on the $t d c$ DNA between $t d c R$ and $t d c A$ (Fig. 5; Goss and Datta 1985), and the in vitro gel-shift and transcription experiments (R.V. Patil and P. Datta, unpublished observations) have confirmed the role of cAMP for $t d c$ gene expression, the nature of the real inducer generated during anaerobic metabolism remains to be established. If $\mathrm{TdcR}$ were to function as a positive activa- 
43

TdcR

Fis

Fis

NtrC

TnpR

Cro

$\mathrm{Hin}$

QTR $\dot{A} \dot{A} L M M G I N \dot{R} G T \dot{L} R K \dot{K} \dot{H} \dot{L}$ $K Q E \dot{A} \dot{A} R L L G W G \dot{R} N T \dot{L} T R \dot{K} L K$ ATEI $\dot{A} H Q L S I A \dot{R} S T V Y K I L E$ QTKT $\dot{A} K D L G V Y Q S A I N K A I H$ RQQLAंIIFGIGVSTĹYRYFP
IN NAAC-HIFSRYLLENKHL

61.

\section{- Helix - Helix-}

Fig. 6. Sequence of a 19 residue TdcR polypeptide and its relationship to the sequence of other DNA binding proteins. Below the sequence of TdcR (residues 43-61) are the carboxy-terminal residues from 74-98 of Fis and from 442-470 of NtrC from Klebsiella pneumoniae (Johnson et al. 1988). The helix-turn-helix regions from TnpR, Cro and Hin are taken from Pabo and Sauer (1984). Dots indicate identical amino acids, and the dash designates the gap used to maximize alignment

tor protein, it must, according to the accepted view, bind the inducer, and the protein-inducer complex must subsequently recognize and bind to specific DNA sequence(s) to facilitate transcription. Most prokaryotic transcriptionregulatory proteins examined thus far interact with their respective target DNAs by a helix-turn-helix motif (Pabo and Sauer 1984; Kelley and Yanofsky 1985). Analysis of the TdcR sequence according to the method of Dodd and Egan (1987), developed for the detection of potential DNAbinding regions in proteins, reveals a polypeptide segment (amino acid residues 43-61) that shows significant homology to helix-turn-helix motifs of other DNA binding proteins (Fig. 6). TdcR has the appropriate amino acids, alanine and leucine, at the two most conserved residues (positions 5 and 15) although not at the first hinge amino acid residue (at position 9) which is usually a glycine; in addition, residues serine and arginine occur at high frequencies at positions 11 and 12, respectively, and a nonpolar residue at position 10 (Pabo and Sauer 1984; Dodd and Egan 1987). The entire 20 -amino acid region of TdcR displays $25 \%$ and $35 \%$ identity to the NtrC and Fis polypeptides which activate, respectively, $\sigma^{54}$-dependent promoters associated with nitrogen regulation (Buikema et al. 1985; Drummond et al. 1986) and Hin-mediated DNA inversion in vivo and in vitro (Johnson et al. 1988). Thus, it appears likely that TdcR could potentially function as a DNA binding protein and, in association with the putative inducer, activate $t d c$ transcription.

The putative binding site(s) on $t d c$ DNA for TdcR has not been identified. The untranslated DNA segment between the $t d c R$ and $t d c A$ reading frames (see Fig. 5) contains sequences implicated in $t d c$ gene expression: the CAP site for transcription initiation by the cAMP-CAP complex which is inhibited by the $E$. coli integration host factor (IHF), which binds to the DNA at the IHF site (R.V. Patil and P. Datta, unpublished observations). Experiments with the $t d c B$-lacZ plasmids (Figs. 1, 3) suggested that this region of DNA might also include a $c i s$-sequence needed for the action of the $t d c R$ gene product. The two direct repeat elements, with the consensus sequence 5'-AGPyATAAA-3' at nucleotides $-117 /-124$ and $-129 /-136$ (Fig. 5), are possible candidates for binding of TdcR. This notion is consistent with the observations that the endpoint of the plasmid pSH202 (Fig. 1), which expresses basal level of $\beta$ galactosidase activity in the presence or absence of the $t d c R$ gene product, maps in between the two direct repeats $(G$ at position -128); whereas plasmid pSH240, which includes these direct repeats but lacks a functional $t d c R$ gene product, exhibits low TdcB-LacZ activity in the absence of plasmid-encoded TdcR but shows maximal activity in the presence of $\mathrm{TdcR}$.

The results clearly indicate a genetic role of $t d c R$ for efficient expression of the $t d c$ operon. Further experiments are necessary to understand the biochemical mechanism of transcriptional activation by TdcR, identify its DNA binding site, and establish the identity of the physiological inducer.

Acknowledgements. This work was supported by Public Health Service Grant GM21436 from the National Institutes of Health.

\section{References}

Biggin MD, Gibson TJ, Hong SF (1983) Buffer gradient gels and ${ }^{35} \mathrm{~S}$ label as an aid to rapid DNA sequence determination. Proc Natl Acad Sci USA 80:3963-3965

Buikema WJ, Szeto WW, Lemley PV, Orme-Johnson WH, Ausubel FM (1985) Nitrogen fixation specific regulatory genes of Klebsiella pneumoniae and Rhizobium meliloti share homology with the general nitrogen regulatory gene ntr $C$ of $K$. pneumoniae. Nucleic Acids Res 13:4539-4555

Casadaban MJ, Chou J, Cohen SN (1980) In vitro gene fusions that join an enzymatically active $\beta$-galactosidase segment to amino-terminal fragments of exogenous proteins: Escherichia coli plasmid vectors for the detection and cloning of translation initiation signals. J Bacteriol 143:971-980

Chang ACY, Cohen SN (1978) Construction and characterization of amplifiable multicopy DNA cloning vehicles derived from the P15A cryptic miniplasmid. J Bacteriol 134:1141-1156

Clark-Curtiss JE, Curtiss R, III (1983) Analysis of recombinant DNA using Escherichia coli minicells. Methods Enzymol $101: 347-362$

Datta P, Goss TJ, Omnaas JR, Patil RV (1987) Covalent structure of biodegradative threonine dehydratase of Escherichia coli: homology with other dehydratases. Proc Natl Acad Sci USA $84: 393-397$

Davis RW, Botstein D, Roth JR (1980) Advanced Bacterial Genetics. Cold Spring Harbor Laboratory Press, New York

Dodd IB, Egan JB (1987) Systematic method for the detection of potential $\lambda$ cro-like DNA-binding regions in proteins. $J$ Mol Biol 194:557-564

Drummond M, Whitty P, Wootton J (1986) Sequence and domain relationships of $n t r C$ and nif $A$ from Klebsiella pneumoniae: homologies to other regulatory proteins. EMBO J 5:441- 447

Goss TJ, Datta P (1985) Molecular cloning and expression of the biodegradative threonine dehydratase gene $(t d c)$ of Escherichia coli. Mol Gen Genet $201: 308-314$

Goss TJ, Schweizer HP, Datta P (1988) Molecular characterization of the $t d c$ operon of Escherichia coli $\mathrm{K}-12$. J Bacteriol 170:5352-5359

Grosjean H, Fiers W (1982) Preferential codon usage in prokaryotic genes: the optimal codon-anticodon interaction energy and the selective codon usage in efficiently expressed genes. Gene 18:199-209

Hobert EH, Datta P (1983) Synthesis of biodegradative threonine dehydratase of Escherichia coli: role of amino acids, electron acceptors, and certain intermediary metabolites. J Bacteriol $155: 586-592$

Johnson R, Ball CA, Pfeffer D, Simon MI (1988) Isolation of the gene encoding the Hin recombinational enhancer binding protein. Proc Natl Acad Sci USA 85:3484-3488 
Kelley RL, Yanofsky C (1985) Mutational studies with the trp repressor of Escherichia coli support the helix-turn-helix model of repressor recognition of operator DNA. Proc Natl Acad Sci USA 82:483-487

Ludtke D, Larson TJ, Beck C, Boos W (1982) Only one gene is required for $g l p T$-dependent transport of $s n$-glycerol-3-phosphate in Escherichia coli. Mol Gen Genet 186:540-547

Messing J (1983) New M13 vectors for cloning. Methods Enzymol $101: 20-78$

Miller JH (1972) Experiments in molecular genetics. Cold Spring Harbor Laboratory Press, New York

Pabo CO, Sauer RT (1984) Protein DNA recognition. Annu Rev Biochem 53:293-321

Palchaudhuri S, Patel V, McFall E (1988) DNA sequence of the D-serine deaminase activator gene $d s d C$. J Bacteriol 170:330-334

Schägger H, von Jagow G (1987) Tricine-sodium dodecyl sulfatepolyacrylamide gel electrophoresis for the separation of pro- teins in the range from 1 to $100 \mathrm{kDa}$. Anal Biochem 166:368-379

Schweizer HP, Datta P (1988) Genetic Analysis of the $t d c A B C$ operon of Escherichia coli K-12. J Bacteriol 170:5360-5363

Umbarger HE (1978) Amino acid biosynthesis and its regulation. Annu Rev Biochem 47:533-606

Vieira J, Messing J (1982) The pUC plasmids, an M13mp7-derived system for insertion mutagenesis and sequencing with synthetic universal primers. Gene 19:259-268

Wieslander L (1979) A simple method to recover intact high molecular weight RNA and DNA after electrophoretic separation in low gelling temperature agarose gels. Anal Biochem 98:305-309

Communicated by $\mathrm{H}$. Hennecke

Received March 3, 1989 